Article

\title{
Modelling Facilitates Silvicultural Decision-Making for Improving the Mitigating Effect of Beech (Fagus Sylvatica L.) Dominated Alpine Forest against Rockfall
}

\author{
Petra Kajdiž, Jurij Diaci * and Jernej Rebernik \\ Department of Forestry and Renewable Forest Resources, Biotechnical Faculty, \\ University in Ljubljana, Vecna pot 83, Ljubljana 1000, Slovenia; \\ E-Mails: petra.kajdiz@gmail.com (P.K.); jernej.rebernik@gmail.com (J.R.) \\ * Author to whom correspondence should be addressed; E-Mail: jurij.diaci@bf.uni-lj.si; \\ Tel.: +386-1-320-3533; Fax: +386-1-257-1169.
}

Academic Editors: Rodney J. Keenan and Eric J. Jokela

Received: 10 April 2015 / Accepted: 8 June 2015 / Published: 19 June 2015

\begin{abstract}
In southeast Europe, silvicultural measures for improving forest protective effects against rockfall are often based on unsystematic observation and experience. We compared formalised expert assessment of forest protective effects and silvicultural decision-making with an approach supported by modelling (Rockyfor3D, Rockfor.NET, shadow angle method). The case study was conducted in Fagus sylvatica dominated Alpine forests above the regional road leading to the Ljubelj pass, in Slovenia. We analysed rock sources, silent witnesses, forest structure and regeneration. Expert assessment indicated acceptable protection effects of the forest and their decline in the future. Modelling revealed several road sections endangered by rockfalls. It also indicated subtle differences between silvicultural alternatives: current forest, current forest with cable crane lines, selection forest and non-forested slope. This outcome may be due to short transition zones, small rock sizes, low rock source heights and low resolution of the digital elevation model. Modelling requires more initial input than formalised expert assessment but gives spatially explicit results that enable comparison of silvicultural alternatives, coordination of silviculture and forest operations, and delineation of protection forests. Modelling also supported prioritising of silvicultural measures, where the necessity of silvicultural measures increases with increasing rockfall susceptibility and decreasing long-term stability of stands.
\end{abstract}


Keywords: beech forest; protective function; rockfall; Slovenia; Rockyfor3D; Rockfor.NET; Viewshed

\section{Introduction}

Mountain forests in Alpine countries provide protection from various natural hazards [1]. In the past, the majority of Alpine forests were intensively managed [2] and this maintained or, in the case of overuse, also decreased their protective effects. The terminal developmental stand phase with a high risk of collapse due to natural disturbances was rarely reached. In recent decades, depopulation of mountainous regions, unprofitability of forestry, and avoidance of silvicultural interventions due to complex situations (i.e., conflicts between economic and social functions) have caused forest ageing, overstocking, and a decline in forest health [3]. The prevailing even-aged stand structure is also a result of past large-scale and clear-cut management [4]. These changes have increased the susceptibility of Alpine forests to natural disturbances and decreased their long-term protective effectiveness. Some countries have developed effective countermeasures, including special silvicultural guidelines, protocols for setting priorities, delineation of forests with direct protective functions, and provision of subsidies [5-7].

The improvement of protection efficiency has often been the objective of research in many Alpine countries, especially in coniferous forests [4,6]. Deciduous forests have not received as much attention with respect to their protective function [8-10] despite the fact that they are well represented in many European mountain regions. Most of the research on forest protective functions in Europe has focused on the Alpine region [11], whereas other mountain chains with similar problems have received much less attention [12].

Among the natural hazards in the European Alps, rockfall is one of the most widespread and destructive mass movements [13,14]. It has received a great deal of attention because of its frequency and potential for damage $[8,9,11,12,15,16]$. Rockfall endangers settlements and infrastructure as well as human life. However, rockfall risks can be effectively mitigated by favouring appropriate forest structures [6,16]. In recent decades, several methods for modelling rockfall risks and forest protective effects have been developed [17-19]. Still, most decisions during silvicultural operations in practice are based on observation, stand parameters and experience [10,20]. There is insufficient integration of knowledge from various disciplines such as geology, forestry and civil engineering. Moreover, within the forestry sector there is often a lack of priority setting, and insufficient coordination between silviculture and forest operations.

The purpose of this study is to assess existing and future forest protective effects against rockfall and to develop silvicultural measures based on formalised expert assessment and a susceptibility modelling approach. We set out to determine whether the application of models (Rockyfor3D and Rockfor.NET) would enable better integration of silvicultural practices (for an overview see [21]) with information on rockfall susceptibility and knowledge on forest mitigation effects. We hypothesised that the current forest structure in the research area protects against rockfall, but that the long-term sustainability of protective functions is on the decline. Further, we hypothesised that an integrative approach based on modelling would enable setting priorities for silvicultural interventions, facilitate 
decisions on the use of alternative silvicultural approaches and improve the interface between silviculture and forest operations.

\section{Materials and Methods}

\subsection{Stand and Site Characteristics}

The study area is located on the southern slopes of Rovna Peč (1503 m above sea level, hereinafter referred to m.a.s.1.) in the Karavanke mountain range of the Southern Limestone Alps. The study site covers 24 hectares with an altitude ranging from 1000 to 1400 m.a.s.l. The forests protect an important traffic connection between Slovenia and Austria through the Ljubelj high mountain pass. The southern and southeastern forested slopes have a mean gradient of $34^{\circ}$. The bedrock within the area is predominantly composed of limestone and dolomite. Karst landscape is a fragile natural environment, prone to erosion due to chemical solution of limestone, dominant subsurface drainage and underground caves [22,23]. However, Karavanke Mountains are particularly geologically diverse [24]. Often older succession of sedimentary rocks from Palaeozoic was raised high up and mixed with younger rocks. In our research area, there were many karstic features, especially rocky outcrops, yet no underground caves were detected. Two small streams within the area also indicate mixing of geological substrates.

There are no significant high cliffs above the forest, only rock sources of small and medium heights up to 5-10 $\mathrm{m}$ that are positioned in the upper, middle and lower parts of the forested slope (Figure A1). Undulating terrain with many torrents and ridges plays a significant role in determining the direction of falling rocks, their kinetic energy and deposition distribution.

The dominant tree species were beech (Fagus Sylvatica), Norway spruce (Picea abies) and sycamore maple (Acer pseudoplatanus), followed by European ash (Fraxinus excelsior), whitebeam (Sorbus aria), scotch laburnum (Laburnum alpinum) and goat willow (Salix caprea). The latter three did not have a significant share in the growing stock. The prevailing forest association according to Braun-Blanquet typology is Anemono trifoliae-Fagetum. Most of the forest was mixed with dominant beech with a maximum height of $23 \mathrm{~m}$. The forest structure was even to uneven-aged with some regeneration cohorts.

Temperature data for the study site were collected from the Planina pod Golico climatological station (970 m.a.s.1.) and precipitation data from the Podljubelj meteorological station (658 m.a.s.1.). For calculation of mean values of temperature and precipitation, an average of 32 years from 1980 to 2012 was taken. Mean annual temperature was $6.9^{\circ} \mathrm{C}$. Mean temperature of the coolest month (January) was $-2.2^{\circ} \mathrm{C}$, and the warmest month (July) reached $15.9^{\circ} \mathrm{C}$. Annual precipitation was $1518 \mathrm{~mm}$ with the highest precipitation $(169 \mathrm{~mm})$ recorded in June.

The road through the Ljubelj border crossing is a medium traffic road, located below the study site, traversing the slope. From this road just before the tunnel, a forest road begins and winds its way up to the top of Ljubelj, passing through the study area (Figure A1). Both road sections are endangered by rockfalls, as the trajectories of rocks falling from the rock sources within the study site cross them.

The forests in the study area have seen very little management. There were sporadic selection fellings of trees at the forest edge along both sides of the forest road that goes to the top of Ljubelj pass (as far as the cable of a tractor winch could reach). Besides this, two cable crane corridors were recently installed along which a few small gaps and moderate thinning of mature stands was carried out. The first 
was down the torrent and the second down the reef at the lower part of the area under the forest road. In former times, there were pastures at the top of the mountain with some scattered Norway spruce trees, which today are mature trees with canopies extending to the ground. There was also some coppice management of beech stands just below the pastures. The majority of the forest has been unmanaged for several decades.

\subsection{Recordings}

We established a grid of $75 \times 75 \mathrm{~m}$ with 61 circular plots (radius of $11.28 \mathrm{~m}$ ) within the grid intersections. If the predefined position of the plot fell out of the forest (e.g., rock outcrops, forest road, torrent...), its centre was moved $20 \mathrm{~m}$ eastward. The following general characteristics of the plots were surveyed: slope (in degrees), exposition, type of bedrock, microrelief (concave, convex, plane), macrorelief (slope, plane), stoniness ( $\%$ of the surface), rockiness ( $\%$ of the surface), cover of herbs ( $\%$ of the surface cover), cover of lower, middle and upper layer of trees ( $\%$ of the surface cover), altitude and Global Position System (GPS) coordinates $(Y, X)$.

On the plots, we inventoried all trees with diameter at breast height $(\mathrm{DBH})$ of $1.27 \mathrm{~cm}$ or more to assure compatibility with a forest gap model ForClim (Bugmann, 1996). The following variables were inventoried: tree species, azimuth, distance from the centre of the plot $(\mathrm{m}), \mathrm{DBH}(\mathrm{cm})$, height $(\mathrm{m})$, height of the lower canopy branches $(\mathrm{m})$, number of rocks stopped by the tree and their dimensions (height, width, length), overall damage to the tree (damage type and size, fruit bodies of fungi...) and social status of the tree (upper, middle, lower). On each plot, we established two (north and south) square subplots of $1.5 \mathrm{~m} \times 1.5 \mathrm{~m}$ in size. On north subplots, herbs and regeneration were recorded while on the south subplots just regeneration was surveyed. On each subplot, general characteristics were recorded: slope (in degrees), exposition, micro-relief (concave, convex, plane), height of herbs (in $\mathrm{cm}$ ), stoniness ( $\%$ of the surface), rockiness ( $\%$ of the surface), cover of herbs ( $\%$ of the surface cover) and cover of woody debris over $1 \mathrm{~cm}$ in diameter (\% of the surface).

Regeneration was tallied according to the species and height classes: (1) seedlings older than one year and lower than $20 \mathrm{~cm}$, (2) seedlings of height classes 21-50 cm and (3) 51-130 cm, and (4) saplings from $131 \mathrm{~cm}$ in height to $1.27 \mathrm{~cm}$ in $\mathrm{DBH}$. We also scored seedling damage due to ungulate browsing according to three levels: 1 -no or little damage: $<10 \%$ of lateral shoots browsed; 2 - partially damaged seedlings: more than $50 \%$ of lateral shoots damaged or terminal shoot damaged; 3 - severely damaged seedlings: terminal and $>50 \%$ of lateral shoots damaged. We counted the mean number of retained stones behind the trees on each plot. Only trees that actually stopped rocks were taken into account. Plots were then divided into three categories according to the mean number of retained stones: (1) 0-2.5 stones per tree, (2) 2.5-5 and (3) 5-7.4 stones per tree. For the entire area, all rock sources were determined and mapped (Figure A1). For each rock source, bedrock type and its dimensions (length, width and height) were determined. For measurements, we used a compass, inclinometer, measuring tape, diameter tape, vertex (for measuring distance and heights) and a tree caliper.

We surveyed the whole research area for the active rockfall sources. We measured and mapped the approximate shape of each rockfall source, measured its height and mean size of falling rocks and assessed the type of geological substrate. Each active rockfall source was georeferenced. 


\subsection{Expert Assessment of Forest Protection Functions and Target Forest Profiles}

We carried out a review of protection forest management guidelines and extracted target forest profiles for effective protection against rockfall on comparable sites. According to the Swiss approach [6,21], target conditions are specific regarding groups of natural hazards involved (e.g., snow avalanches; landslides, erosion and debris flow; rockfall; torrents and floods) as well as in regard to the forest/site typology. Target conditions are formalized in target profiles which propose standards with regard to species mixture, horizontal and vertical stand structure and regeneration. They distinguish between two sub-profiles for both hazard- and site-related target profiles. The first describes an "ideal" forest condition and the second a "minimum" condition. The "ideal" profile forms the basis for setting the long-term silvicultural objectives, and the "minimum" profile serves as the lower threshold for carrying out silvicultural interventions.

The parameters introduced by Motta [1] were used to describe forest stand suitability for protectiveness and silvicultural stability. These parameters are divided into four categories: stand history, stand structure, dominant trees and natural regeneration. To determine diameter distribution shape of the study forest for evaluation of the sustainability of the selection structure, the method by Janowiak [25] was used. In terms of regeneration, the observed values for regeneration classes were compared with target values for selection forests on similar sites and altitude belt as proposed by Frehner et al. [21] and Bachofen [26]. Equilibrium growing stock for selection forest was estimated from the recommendations by Schütz [27]. The same source was used as a basis for constructing the idealized selection forest structure used in comparing scenarios.

\subsection{Modelling Rockfall Susceptibility}

Integration of rockfall susceptibility assessment into silvicultural planning was one of the main goals of this study. For the purpose of rockfall susceptibility assessment, we applied the shadow angle method and two simulation models. For the production of risk maps with the shadow angle method, we applied the Viewshed Function in ArcMap software. As the input data for the function, we used the digital terrain model at a resolution of $12.5 \times 12.5 \mathrm{~m}$ (the same was also used in the two simulation models) and a raster map with points denoting rock sources. We added five meters of height to the source points, which was the average height of the rock sources above the surface. The result was the maximal shadow angle. The vertical (shadow) angle was set to $32^{\circ}$ and the horizontal (as the deviation to the left and right of the vertical angle) to $15^{\circ}$.

Another model that we used for simulations was Rockfor.NET. It is a tool for quickly rating the protective capacity of a forest stand against rockfall. It takes into account rock, slope and forest characteristics [19]. Data necessary for the model are as follows: dimensions of the dominating rocks (length, width and height: $0.5 \times 0.6 \times 0.6 \mathrm{~m})$, rock density $\left(2700 \mathrm{~kg} \cdot \mathrm{m}^{-3}\right.$ for limestone and $2800 \mathrm{~kg} \cdot \mathrm{m}^{-3}$ for dolomite), rock shape (rectangle), mean slope angel (degrees), length of forested and non-forested slope on the trajectory of falling rock $(\mathrm{m})$, height of rock source $(\mathrm{m})$, mean density of the forest stands the rocks pass through on their way down $\left(\mathrm{N}\right.$ trees $\left.\mathrm{ha}^{-1}\right)$, mean DBH of the transition forest stands $(\mathrm{cm})$, proportion of tree species of transition forest stands (\%). Rockfor.NET firstly estimates the degree of protection of a forest to rockfall given the defined conditions. Secondly, it provides the target profile 
(minimum and ideal) of the forest given those conditions. The degree of protection is represented by the maximal kinetic energy of falling rocks [28].

We used Rockfor.NET for each of the rock sources at the study site to determine the potential threat to the road below. For larger rock sources and rock sources from where falls may occur in different directions, we used several source points and performed several calculations. In the case of the large kinetic energy values on the upper (forest) road, we performed another calculation where the trajectory was extended to the regional road. The Rockfor.NET tool is not able to calculate rockfall trajectories by itself. Rockfall trajectories must be determined subjectively and are represented by straight lines running from rock sources to the road. The endangered area of the road is then the intersection of the road and $15^{\circ}$ deviation in both directions from the straight trajectory lines.

Rockyfor3D is a simulation model that calculates trajectories of single, individually falling rocks in three dimensions (3D). For the purposes of the model, the whole area was divided into polygons based on the methodology developed by Doreen [29]. The characteristics of the polygons were as follows: slope angle (in degrees), zone (rock source, transition zone, deposition zone), shape and dimensions of the dominating rocks (rectangle, $0.5 \mathrm{~m} \times 0.6 \mathrm{~m} \times 0.6 \mathrm{~m}$ ), soil type (fine material thicker than $100 \mathrm{~cm}$, fine material thickness in the range from 10 to $100 \mathrm{~cm}$, forest road, coarse scree or talus cover, asphalt road, bedrock), surface roughness (obstacle height normal to the slope surface $(\mathrm{m})$ that block encounters in $70 \%, 20 \%$ and $10 \%$ of the cases during a rebound on the slope surface; Figure A1), characteristics of the forest (tree density in stems $\mathrm{ha}^{-1}$, mean diameter in $\mathrm{cm}$, the proportion of coniferous and deciduous trees in \%). Before running simulations in Rockyfor3D, the following parameters were set: number of simulations: 3000 , variation of rock volume: $\pm 10 \%$, additional initial fall-height: $5 \mathrm{~m}$.

The study area was also divided into stands. For this purpose, we took into account field observations, orthophoto maps and infrared orthophoto maps and described tree structure of three height layers, diameter structure of the extended DBH classes (A: 10 to $30 \mathrm{~cm}, \mathrm{~B}: 30$ to $50 \mathrm{~cm}, \mathrm{C}$ : above $50 \mathrm{~cm}$ ), stability of individual layers (1: good, 2: satisfactory, 3: poor), size and shape of the canopies of coniferous and deciduous trees, canopy cover, average age of trees, regeneration (tree species at the surface in \%) and tree damage from logging.

We performed simulations with different forest cover and silvicultural system scenarios: non-forested slope, current forest, current forest with anticipated cable crane lines and ideal selection forest. Anticipated cable crane lines were created according to existing practice relatively perpendicularly to the slope since we wanted to verify their effects on the rockfall susceptibility.

Modelling results pointed to several rockfall endangered road sections, while at the same time it indicated that the forest protective effect could not be improved. Therefore, an additional simulation with rockfall retaining nets, installed just above the regional road in all the road sections where rocks traversed the road, was carried out. Rockyfor3D results indicated highest mean rock energies up to $300 \mathrm{~kJ}$ and maximum jump heights of the rocks $3.3 \mathrm{~m}$ at a $98 \%$ confidence interval at the position of the rockfall retaining nets. Therefore, net energy was set to $500 \mathrm{~kJ}$ and height to $3 \mathrm{~m}$. In addition, a local expert independently advised installation of similar sized nets. These maps were created in geographic information systems (GIS) program and converted to raster maps with System for Automated Geoscientific Analyses (SAGA GIS). For comparison of the results of susceptibility rate for different scenarios, we used the following parameters: mean kinetic energy of falling rocks (in kJ, shown on the profile chart) and number 
of deposited rocks (shown on map produced with the open-source geographic information system application QGIS).

\section{Results}

\subsection{Expert Assessment of Present and Future Forest Protective Function against Rockfall}

We analysed the sustainability of forest protective functions according to four criteria: stand history, stand structure, dominant trees and natural regeneration. From the stand history, presented within the methods section, several aspects important for forest protective functions are evident - firstly, past forest use with grazing favoured conifers. Moreover, in the last several decades there has been no regular forest management over the entire study area. Both of these facts are not conducive to the provision of forest protective functions. Historical coppice management in parts of the stands and sporadic selection management along the road, on the other hand, added some favourable uneven-aged structure to the forest.

Existing forest structure was compared with proposed target profiles for protection against rockfall that were compiled from guidelines for management of forests with direct protective function on comparable alpine Fagus sylvatica dominated forest sites (see methods section). Favourable and unfavourable elements of forest structure were found. The analysis of vertical structure, based on the criteria of dividing the stand layers into according thirds of maximum stand height, showed that $45 \%$ of trees were in the upper, $22 \%$ in the middle and $33 \%$ in the lower stand layer. This indicated that in spite of well-developed and rarely discontinuous upper canopy cover, trees in lower layers were present, which indicated opportunities for developing uneven-aged structure. The average growing stock was $510 \mathrm{~m}^{3} \mathrm{ha}^{-1}$ with a density of 1424 trees $\mathrm{ha}^{-1}$. The growing stock was above equilibrium level for selection or group selection forest on this site type $\left(250-280 \mathrm{~m}^{3} \mathrm{ha}^{-1}\right)$. Species mixture and tree density were in line with the target values (Table 1). Further, estimates of vertical structure and stability were within proposed boundaries.

Table 1. Comparison of minimum requirements for the target profile for natural hazard rockfall and alpine mountain Fagus sylvatica forest (site Anemone trifoliae-Fagetum with some narrow area of Ostryo-Fagetum and existing forest stand-sensu [17]).

\begin{tabular}{|c|c|c|}
\hline Attribute & Minimum requirements for the target profile & Existing forest \\
\hline Stand mixture & $\begin{array}{l}60 \%-100 \% \text { deciduous trees }(50 \%-100 \% \text { Fagus sylvatica, } \\
0 \%-30 \% \text { Picea abies })\end{array}$ & $\begin{array}{c}76 \% \text { deciduous trees } \\
(35 \% \text { Fagus sylvatica, } \\
22 \% \text { Picea abies })\end{array}$ \\
\hline Vertical structure & $\begin{array}{l}\text { Enough trees with growth potential in at least two DBH } \\
\text { classes per hectare }\end{array}$ & yes \\
\hline Horizontal structure & 300 trees per hectare with $\mathrm{DBH}$ over $24 \mathrm{~cm}$ & 327 trees \\
\hline Stability & $\begin{array}{l}\text { Half of all trees should have a symmetric crown, vertical } \\
\text { trunk and good anchoring }\end{array}$ & yes \\
\hline $\begin{array}{l}\text { Regeneration } \\
\text { conditions }\end{array}$ & Competitive herbs cover less than $1 / 3$ of the entire area & $30 \%$ \\
\hline
\end{tabular}


Table 1. Cont.

\begin{tabular}{clc}
\hline Attribute & Minimum requirements for the target profile & Existing forest \\
\hline $\begin{array}{c}\text { Regeneration: } \\
10-40 \mathrm{~cm} \text { high }\end{array}$ & 10 beech seedlings per acre (one every 3 meters) & 24 beech seedlings \\
\hline $\begin{array}{l}\text { Regeneration: } \\
40 \mathrm{~cm} \text { high to }\end{array}$ & $\begin{array}{l}\text { Two regeneration cones per hectare of } 0.02-0.05 \text { ha } \\
\text { in size (one cone every } 75 \text { meters or at least } 4 \% \text { cover } \\
\text { of regeneration) }\end{array}$ & yes \\
\hline
\end{tabular}

DBH, diameter at breast height.

The most frequent species in tree density $(>1.27 \mathrm{~cm}$ in DBH) was Fagus sylvatica with $43 \%$, followed by Picea abies with $16 \%$, Fraxinus excelsior with $12 \%$ and Acer pseudoplatanus with $4 \%$. The percentage of other broadleaves and other conifers amounted to $24 \%$ and $1 \%$, respectively. Average height/DBH ratio (HD) for all trees was 107, and 102 for trees within the upper stand layer. The mean percentage of the crown depth for dominant trees was 35\%. Almost 10\% of trees were damaged (broken or dry top, dying tree). Regarding the individual tree species, Fagus sylvatica was more damaged (15\%) than Picea abies (6\%).

The shape of the overall DBH distribution (Figure 1) indicated substantial deviation from negative exponential or rotated-sigmoid distribution, which are typical for selection or group selection forest.

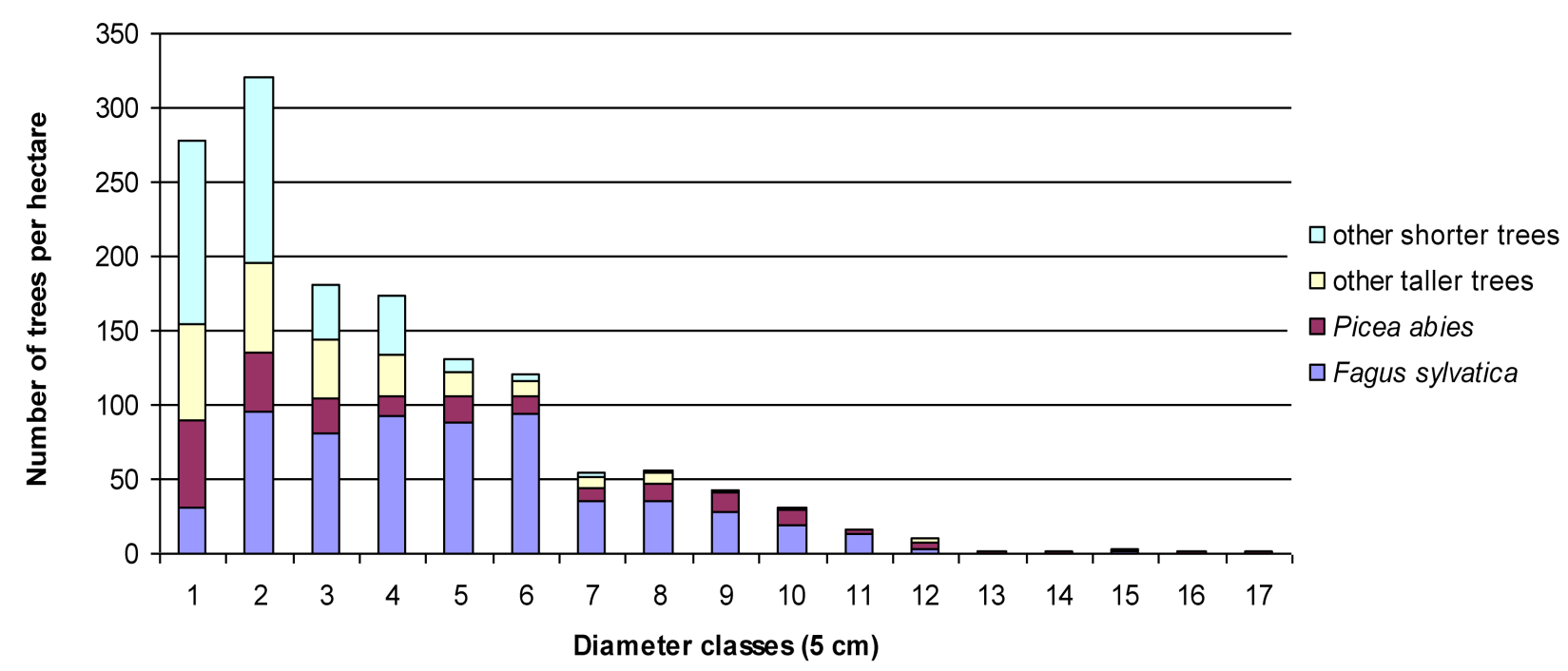

Figure 1. Frequency distribution of trees per diameter at breast height (DBH) class and hectare. The group "other taller trees" includes: Acer pseudoplatanus, Fraxinus excelsior, Abies alba, Larix decidua, Pinus nigra. The group "other shorter trees" includes: Sorbus aria, Laburnum anagyroides, Betula pendula, Salix caprea, Alnus incana, Sorbus aucuparia, Prunus avium, Rhamnus fallax, Amelanchier spichata, and Pinus mugo.

The best fitting significant model for the BDH distribution was:

$$
N=-1.800 \times \mathrm{DBH}^{2}+0.902 \times \mathrm{DBH}^{3}
$$


where $N$ represents the number of trees per hectare in a particular DBH class and DBH represents diameter class midpoint. The distribution shape for this function was variable. Therefore, the second best-fitting significant model was selected, which was a negative exponential:

$$
N=-0.710 \times \mathrm{DBH}
$$

Both the numerical method and visual assessment indicated deviations of DBH structure from target distribution shape. Moreover, the forest was not entirely homogeneous in terms of forest site. Namely, the extreme sites in the near vicinity of scattered rock sources were overgrown by tree species that cannot attain large dimensions (i.e., other shorter trees in Figure 1), but they were included in the sample. When assessing DBH distribution shape without shorter trees, the distribution resembled the unimodal shape and indicated a tendency towards even-aged forest. Given the history of non-management, this was expected.

Competing herbs were on average $16 \mathrm{~cm}$ tall and covered $30 \%$ of the forest floor. On average, $7 \%$ of the forest floor was covered by woody debris with a DBH over $1 \mathrm{~cm}$. Coarse woody debris may serve as a future seedbed for Picea abies and Abies alba regeneration. However, all specimens of regeneration with $\mathrm{DBH}$ less than $1.27 \mathrm{~cm}$ were damaged by ungulates. If we consider only the most severe damage class, then $57 \%$ of beech, $86 \%$ of spruce, $88 \%$ of maple and $100 \%$ of fir seedlings were damaged. The comparison of seedling densities with target values (Tables 1 and 2) showed that the densities for the smallest and tallest classes were within the proposed interval, while the density of the medium size class was below the threshold.

Table 2. Number of seedlings in size classes by species $\mathrm{ha}^{-1}$. Target values were estimated from Duc [20] and Bachofen [21].

\begin{tabular}{cccc}
\hline & \multicolumn{3}{c}{ Size class (height in cm) } \\
\hline Species & $0-20$ & $21-50$ & $51-130$ \\
\hline Fagus sylvatica & 1587 & 847 & 0 \\
Picea abies & 212 & 106 & 423 \\
Abies alba & 5291 & 0 & 0 \\
Acer pseudoplatanus & 24,021 & 635 & 423 \\
Sum & 31,111 & 1588 & 846 \\
Target & $17,000-35,000$ & $2600-18,000$ & $600-6000$ \\
\hline
\end{tabular}

Overall, we can assess regeneration as marginally acceptable, due to the low light environment indicated by high growing stock, overbrowsing and low densities in the medium height class. Regarding all criteria for forest protective function against rockfall, we can evaluate the existing forest protective function against rockfall as satisfactory. However, several elements indicated (e.g., regeneration, DBH distribution shape and growing stock) that protection is not safeguarded in the long term.

\subsection{Modelling Forest Protective Functions against Rockfall and Assessment of Silvicultural Scenarios}

In the previous section, the traditional approach based on the expert assessment of the forest protective function against rockfall indicated acceptable existing protection but a need for improvement in the sustainability of the forest protective role (i.e., decrease the risk for natural disturbance) with silvicultural 
interventions. We applied a modelling approach to verify expert assessment, to spatially explicitly set priorities for silvicultural interventions and to compare different silvicultural alternatives.

The final result of the shadow angle method was a map of maximum rockfall reach (Figure A1). The map indicated that nearly the entire section of the regional road under research was endangered. In addition, the middle part of the forest road was almost continuously endangered, while the lower and upper parts were outside the danger zone. The same rock source points were used for Rockfor.NET modelling. From the results shown in the rockfall susceptibility map (Figure 2) and outcomes for individual rock sources (Table A1), sections of road with different maximum kinetic energy of rocks can be identified. The most endangered road sections are coloured red and are particularly evident, thus there is significant rockfall susceptibility. The regional road with denser traffic is especially endangered by rock sources 7 , 15 and 27. If the results are compared with the shadow angle method (Figure A1), it can be seen that most road sections with the highest rockfall susceptibility fall within the red coloured areas of the maximum rockfall reach.

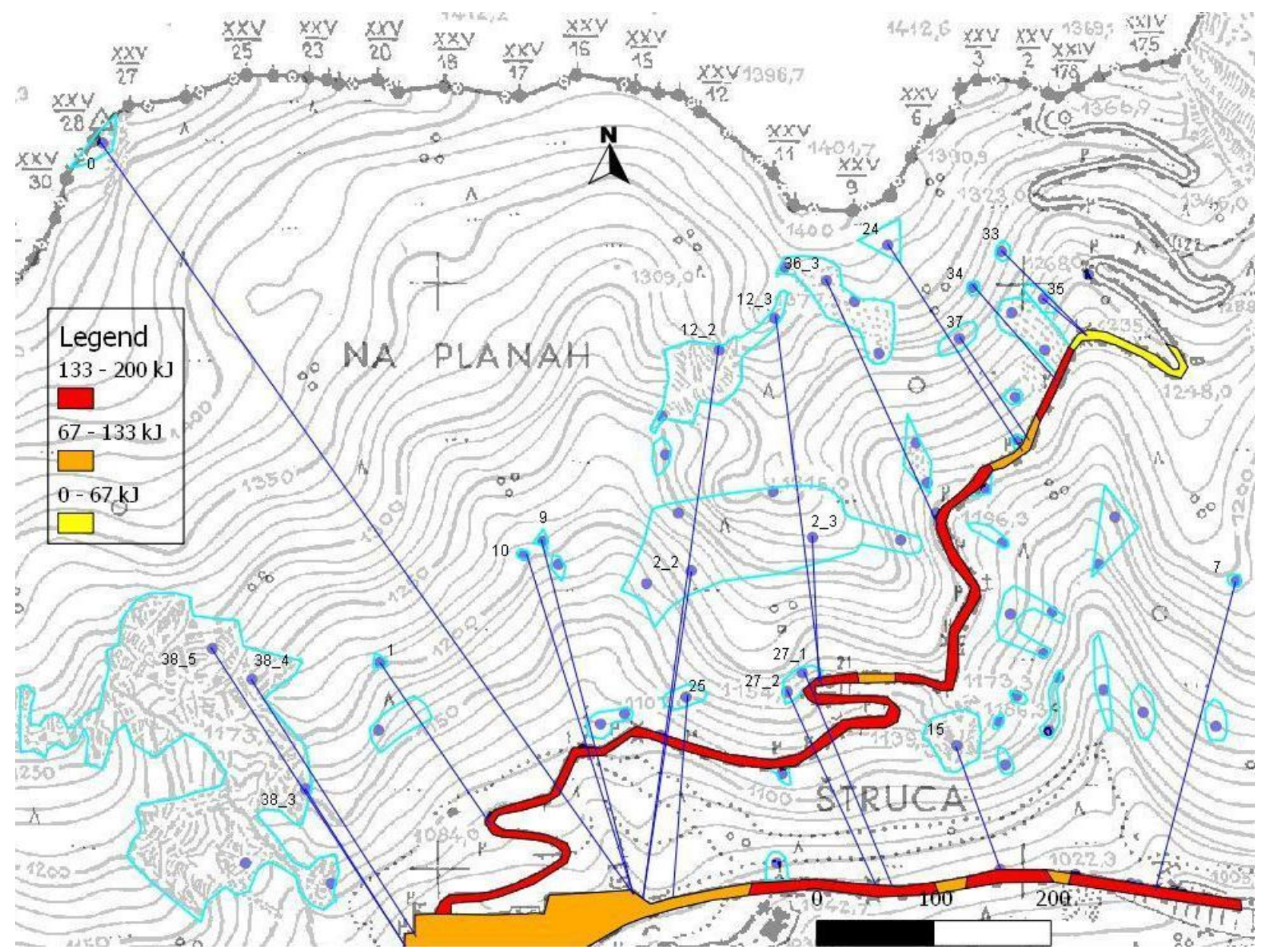

Figure 2. Rockfall susceptibility map based on the results of the Rockfor.NET model. Rock sources are outlined with light blue colour and with dark blue initial points of rockfall trajectories. Dark blue lines represent Rockfor.NET trajectories. Sections of the road are coloured according to the three susceptibility classes based on maximum kinetic energy of rocks in kilojoule $(\mathrm{kJ})$. The deviation in both directions from the straight trajectory lines was $15^{\circ}$. 
Within the framework of Rockyfor3D modelling, we firstly assessed the long-term risk of rockfall with an analysis of the non-forested slope scenario (Figure 3). Taking into account the mean energy of falling rocks, we defined three forest areas with a section of road lying below (Figure A2): (1) with the highest need for direct protective effects (mean kinetic energy 110-333 kJ; red and orange coloured classes of susceptibility in Figure 3), (2) with an intermediate need for protective effects (0-110 kJ; yellow coloured class of susceptibility) and (3) with no need for protective effects ( $0 \mathrm{~kJ}$; transparent). With this analysis, we aimed to delineate forests in the transition zone between rock sources and road sections with the highest risk of rockfall. Within these zones, the forest can significantly reduce the risk of rockfall; therefore, these forest stands should be close to the target profiles. Deviation from the target profiles indicates a high priority for silvicultural measures. On the other hand, areas with no need for protective effects against rockfall indicate stands with low priority of silvicultural measures or areas with no restrictions for silviculture or forest operations regarding direct protection functions. The forest areas denoted yellow in Figures 3 and A2 indicate forest areas that fall between both extremes.

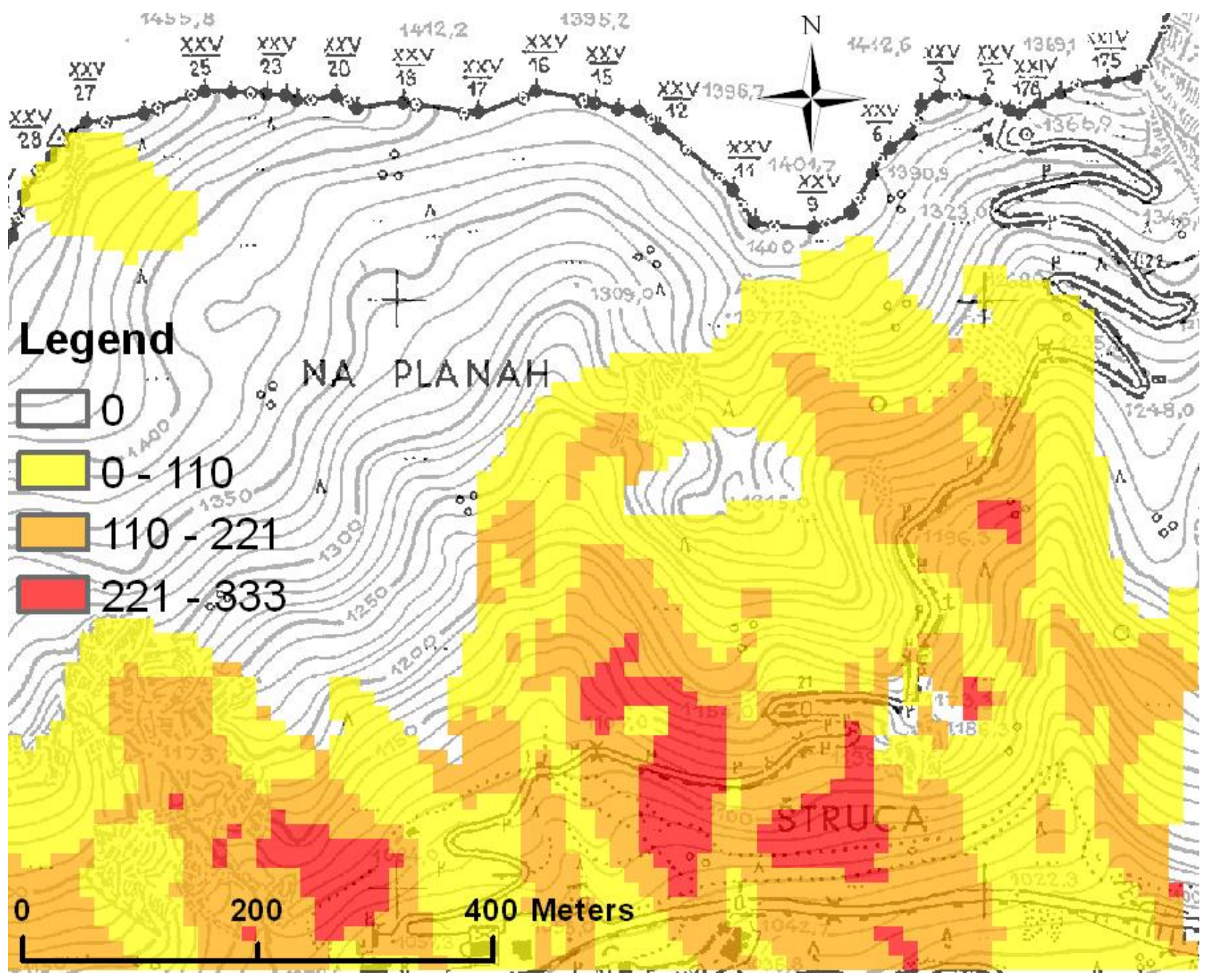

Figure 3. QGIS map of mean kinetic energy of falling rocks for non-forested slope scenario (in kilojoule $(\mathrm{kJ})$ ).

Further, we compared scenarios for the non-forested slope with scenarios for the ideal target structure of selection forest, current forest and current forest with cable crane lines. The latter were installed within 
the areas of highest priority for silvicultural intervention (Figure A2). The profile chart of the mean kinetic energy (Figure 4) indicated that the highest mean kinetic energy of falling rocks corresponded to the non-forested slope scenario. Although this was expected, the differences between forested and non-forested slopes were relatively small. The same was also true for the other scenarios. The next highest kinetic energy of falling rocks was estimated for the current forest with cable crane lines scenario, followed by the selection forest scenario, while the lowest kinetic energy of falling rocks (i.e., best protective role) was estimated for the current forest scenario.

Taking into account silent witnesses, the results showed a good match between the most endangered areas according to Rockyfor3D and the small red circles showing the plots with the highest number of retained stones by trees. The majority of the plots with the highest numbers of retained stones were within or close to the red and orange susceptibility areas of the Rockyfor3D results (Figures 5 and 6).

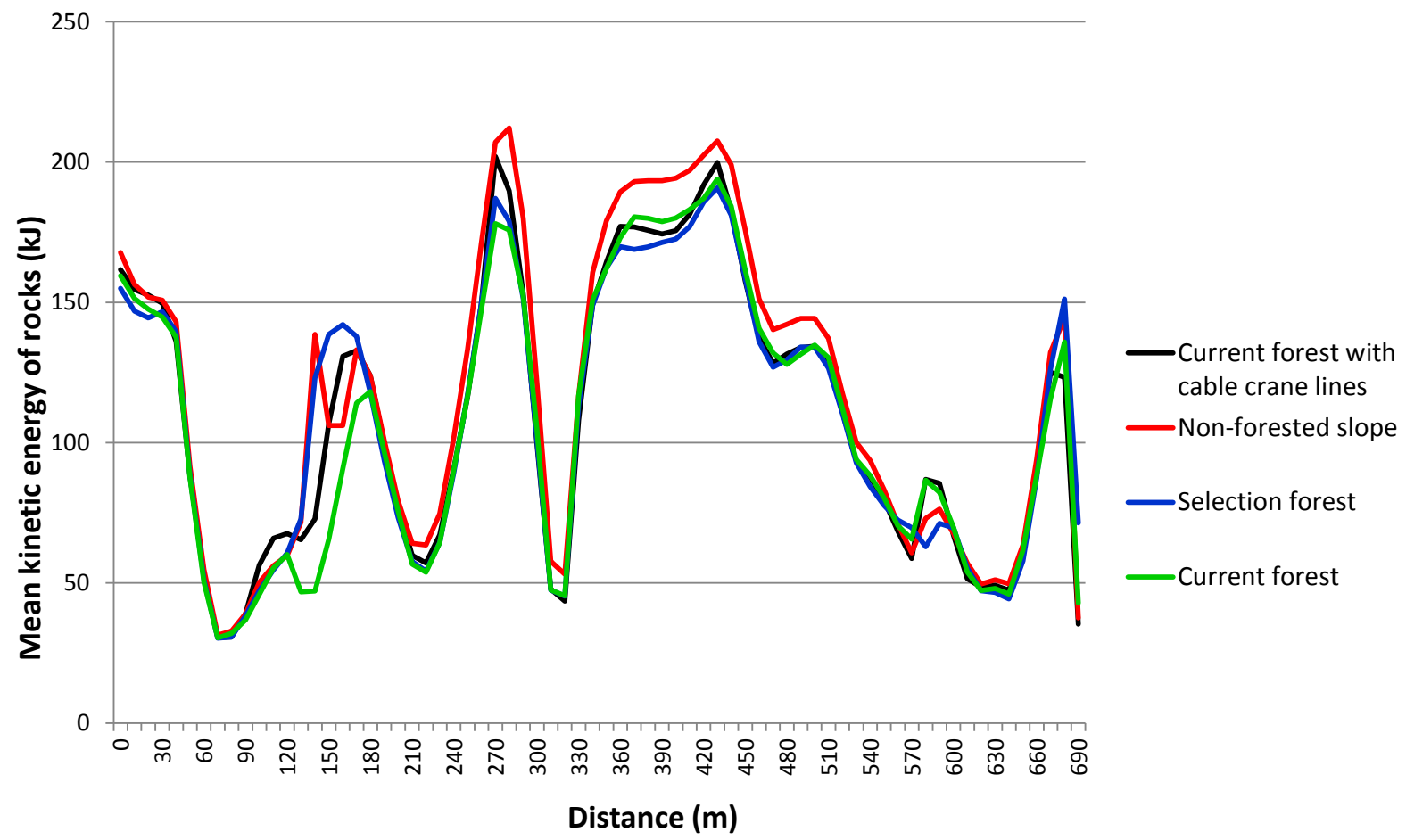

Figure 4. Profile chart of mean kinetic energy in kilojoule $(\mathrm{kJ})$ of rocks on the main road for four forest management scenarios. Distance was measured along the regional road from the tunnel and plateau indicated on the left hand side of the Figure 2 towards sharp bend on the right hand side. 


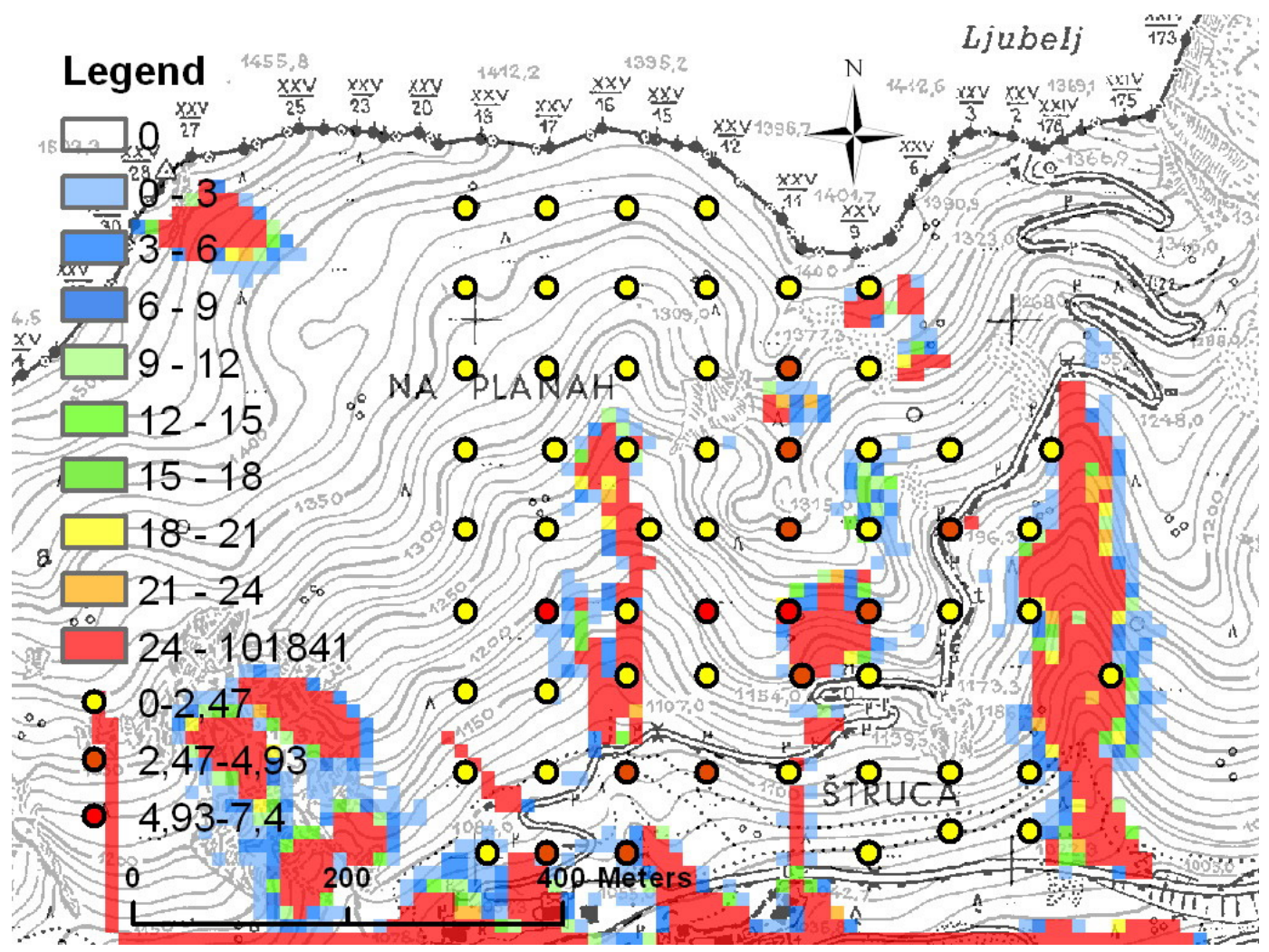

Figure 5. Number of deposited rocks for the non-forested slope scenario (coloured) and silent witnesses (i.e., number of retained stones per tree, labeled by coloured circles).

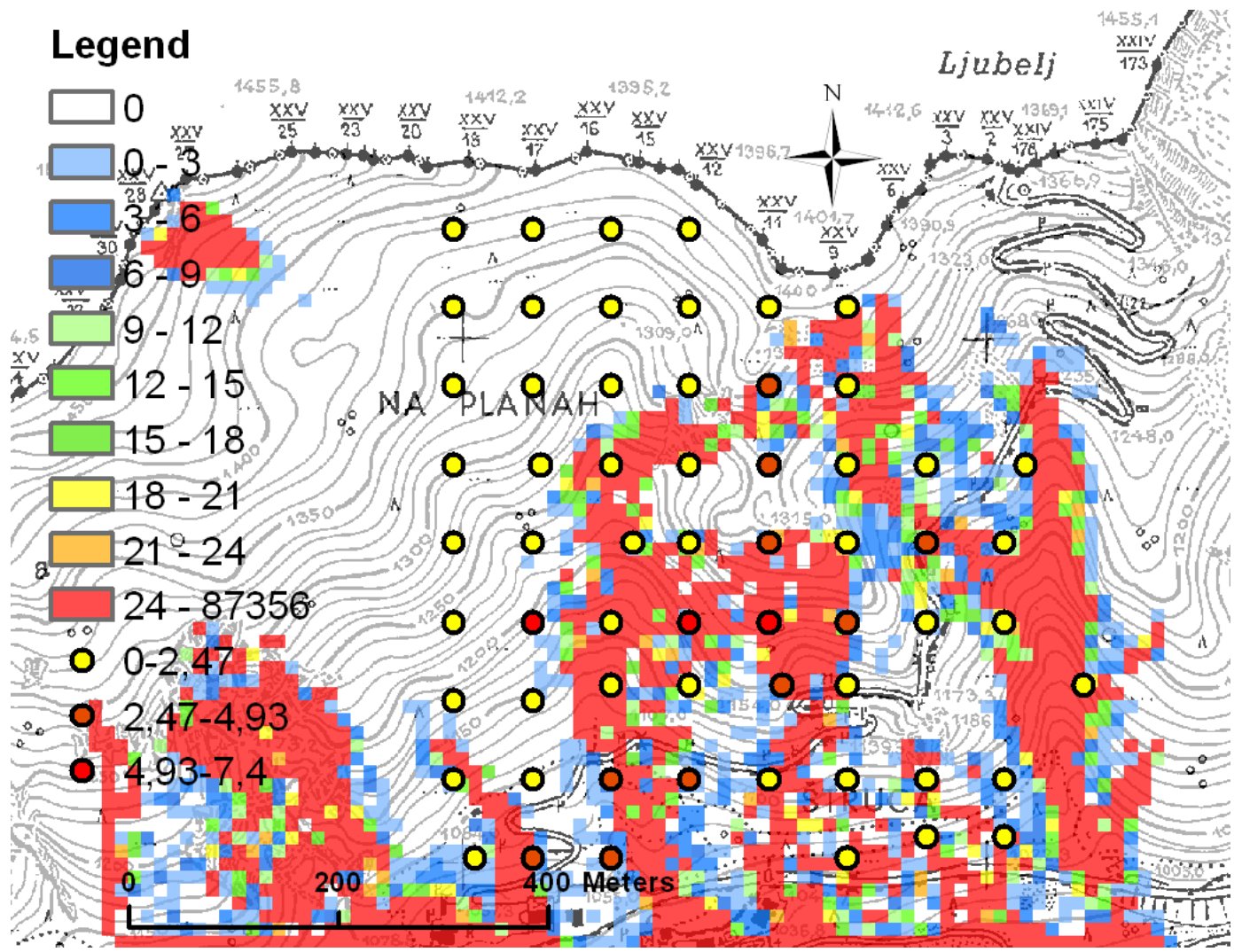

Figure 6. Number of deposited rocks and silent witnesses (number of retained stones per tree, labeled by coloured circles) for the current forest scenario. 
Simulation of deposited rocks showed slightly different results for different scenarios in comparison to the mean energy of rocks. The highest rockfall susceptibility for both indicators was for the non-forested slope scenario, followed by cable crane lines, while current and selection forests exchanged positions depending on the susceptibility indicator selected (Table 3). Still, overall differences were relatively small.

Table 3. Comparison of rockfall susceptibility of regional road between different forest management scenarios (scenario with 1.362.000 released rocks).

\begin{tabular}{cccc}
\hline Scenario & $\begin{array}{c}\text { Mean kinetic energy } \\
\text { of rocks on the road } \\
\text { (kilojoule }(\mathbf{k J}) \text { ) }\end{array}$ & $\begin{array}{c}\text { Average number of } \\
\text { deposited rocks on } \\
\text { the road }\end{array}$ & $\begin{array}{c}\text { Percent of rocks } \\
\text { which reached } \\
\text { the road }\end{array}$ \\
\hline Non-forested slope & 116.7 & 17,091 & 9.5 \\
Current forest & 106.3 & 13,073 & 7.3 \\
Forest with cable crane lines & 109.3 & 13,332 & 7.4 \\
Selection forest & 109.0 & 12,524 & 7.0 \\
\hline
\end{tabular}

Since the regional road is frequented by heavy traffic during summer and the forest cannot provide sufficient protection, we also performed a simulation with protective nets installed above the road. The Rockyfor3D simulation indicated that most rocks were stopped behind the proposed rock retaining net (Figure A3).

\section{Discussion}

\subsection{Existing and Future Forest Protection against Rockfall}

Traditional expert assessment indicated that the protective role of existing forests against rockfall is acceptable and thus confirmed the first hypothesis. It also indicated that future rockfall protection will decline, as indicated by the lack of the medium regeneration class, DBH distribution shape and above equilibrium growing stock. This confirmed the second hypothesis. Similar conditions have been reported for many Alpine countries [1,6]. This is especially problematic in southeast European mountains (e.g., Dinaric Alps, Carpathian Mountains, Mount Olympus) where systems for spatial identification of protection forests, guidelines for target profiles and systems of subventions for silvicultural measures are not yet sufficiently developed [12].

In this study, overbrowsing also hindered the attainment of target profiles since Abies alba and Acer pseudoplatanus, two important species of mountain forest stability [2,6], were not able to recruit into higher regeneration classes. High densities of wild ungulates have been reported as one of the most important silvicultural problems in the Alps [2,30,31].

The shadow angle method and the two susceptibility modelling approaches (Rockfor.NET, Rockyfor3D) only partially confirmed the first hypothesis. Namely, all methods indicated that the protective role of existing forests against rockfall is insufficient in some road sections. Furthermore, Rockyfor3D scenarios indicated that the long-term protective role cannot be significantly improved. 


\subsection{Expert Assessment vs. Modelling}

Traditional expert assessment underestimated the rock fall susceptibility. Moreover, maps of mean kinetic energy of rocks, the profile chart of mean kinetic energy for the regional road and number of deposited rocks generated by modelling showed great variability in rockfall susceptibility along the road. This has several important implications. Firstly, it can significantly improve the spatial identification of protection forests, and it can help in prioritising silvicultural operations [20]. Moreover, it can point to areas where the forest cannot offer sufficient protection against rockfall and where technical measures are needed [18]. In this study, we installed imaginary rockfall retaining nets above the most endangered section of the regional road, which stopped most of the rocks as indicated by the Rockyfor 3D simulation.

Simulation of different silvicultural alternatives yielded expected results, with the non-forested slope scenario offering the lowest protection against rockfall according to all comparisons, followed by the current forest with cable crane lines, whereas the other two scenarios slightly shifted their positions within each criteria selected. The importance of forest protection against rockfall versus non-forested slope has been confirmed in several studies $[18,32,33]$. Still, the difference between current forests, selection structure - which is often quoted as stable [11,27,34] and non-forested slopes appears to be relatively small in this study. We see several possible reasons for this outcome. Firstly, the forested transition zones in this study were relatively short in comparison to those in other studies. The lengths of the transition zone in other studies were, for example, 302 and $224 \mathrm{~m}$ in the study of Dorren et al. [32], $270 \mathrm{~m}$ in the study of Bigot et al. [33], and $325 \mathrm{~m}$ in the study of Wehrli et al. [35]. The average transition zones in this study were about $195 \mathrm{~m}$ in length but were substantially shorter above some sections of the regional road. Rock sizes and the mean height of rock sources in this study were also somehow smaller compared to studies in other regions $[18,33,35]$. Moreover, at the time of the study only a relatively low resolution digital elevation model $(12.5 \mathrm{~m} \times 12.5 \mathrm{~m})$ was available for the area, while Stoffel et al. [18] propose a digital elevation model (DEM) with a resolution of $5 \mathrm{~m} \times 5 \mathrm{~m}$. Low resolution DEM may also lead to overestimation of the rockfall susceptibility. Relatively small and scattered rock sources, such as those in this study, have rarely been modelled but are quite frequent within the peripheral zone of the Alps and other mountain chains.

Spatially explicit results may be achieved without susceptibility modelling based on silent witnesses (e.g., evaluation of retained stones per tree, rockfall damage to trees). This can be quite sampling intensive, whereas modelling can yield quicker and more precise results. In this study, comparison of simulated deposited rocks and the number of retained stones per tree yielded similar results (see [18,32]). On the other hand, modelling requires higher investment of time for preparation of all necessary inputs. Still, the output — spatially explicit maps of rockfall susceptibility — are more objective and may be used for many purposes; for example, delineation of protection forests, assessing silvicultural scenarios and setting silvicultural priorities. The latter could be estimated with a cross-section of the rockfall susceptibility map with the forest stand map, where the long-term mechanical stability of the stand is shown $[1,6]$. The higher the potential susceptibility and the more unstable the forest stands are (i.e., they show the highest deviations from target profiles), the greater the necessity of silvicultural measures. This applies if the stand stability and the effectiveness of its protective role can be improved, which is not always the case. Otherwise, artificial defence constructions are needed (e.g., rockfall retaining nets, 
terraces). The quantity of required information and knowledge increases from the shadow angle method, through Rockfor.NET to Rockyfor3D. However, the reliability of the results increases even more steeply in the same direction.

Susceptibility maps may also help in solving traditional tensions between silviculture and forest operations and in designing optimal cable crane corridors. For example, in protection forests, cable crane corridors should be set diagonal to the slope direction [20]. However, this significantly increases skidding costs and may damage the remaining stand and soil. Contrary to our expectations, this study indicated only small differences in rockfall mitigating effects between forest stands with several imaginary cable crane corridors that were placed vertically (Figure A2) and ideal selection forest structure. This was likely due to the short forest transition zones in this study. Despite these results, a horizontal or oblique positioning of cable cranes is advisable due to the special caution required for stands above the most endangered road sections. On the other hand, no silvicultural interventions for improvement of forest protective effects are required in forest areas outside transition zones and can be left for natural development or managed without restrictions. If this is the case, then placing cable crane corridors vertically could significantly reduce the cost of skidding.

\section{Conclusions}

In southeast Europe, protection against rockfall is also quite important within the eastern peripheral Alps and within mountain chains outside the Alps. Here, unlike the Central Alps, the rock sources are often smaller, lower and more diffusely distributed within forests and forest transition zones are shorter. Forests are often dominated by deciduous trees, especially Fagus sylvatica, which offers better protection against rockfall than conifers. However, its management on steep terrain is challenging due to the eccentricity of tree architecture and the resulting difficulty of directed felling. Silvicultural decisions for improvement of forest protective functions are often based on unsystematic observation and experience; formalized decision-making and modelling are rarely applied. This study indicated similarities as well as dissimilarities between outcomes of formalised expert decision-making regarding forest protective functions against rockfall and approaches based on rockfall susceptibility modelling. The former can be achieved with fewer resources, while modelling requires more initial inputs and knowledge but gives more reliable and useful results in the long term. Modelling allows integration of geological, engineering, silvicultural and technological knowledge and thus should lead to better overall decisions. It also provides important support for delineation of protection forests. Still, the integration of modelling into daily silvicultural practice is a challenging and long-term task. In the meanwhile, formalized decision-making should represent the minimal support for sound silvicultural decision-making within forests with direct protective functions. To achieve this, development of adapted guidelines for beech dominated mountain protection forests for specific regions of southeast Europe is needed.

\section{Acknowledgments}

The authors gratefully acknowledge the help, advice and comments from Dejan Firm and Tihomir Rugani. This research was funded by the Slovenian Research Agency and Ministry for Agriculture, Forestry 
and Food, Research Program Young Researchers and the project assessment and optimization of planning and realisation of young forest tending.

\section{Author Contributions}

Initial ideas and financing of the research: Jurij Diaci, Petra Kajdiž; data compilation and evaluation: all authors; manuscript drafting: Jurij Diaci, Petra Kajdiž; all authors contributed to revising successive drafts.

\section{Conflicts of Interest}

The authors declare no conflict of interest.

\section{Appendix}

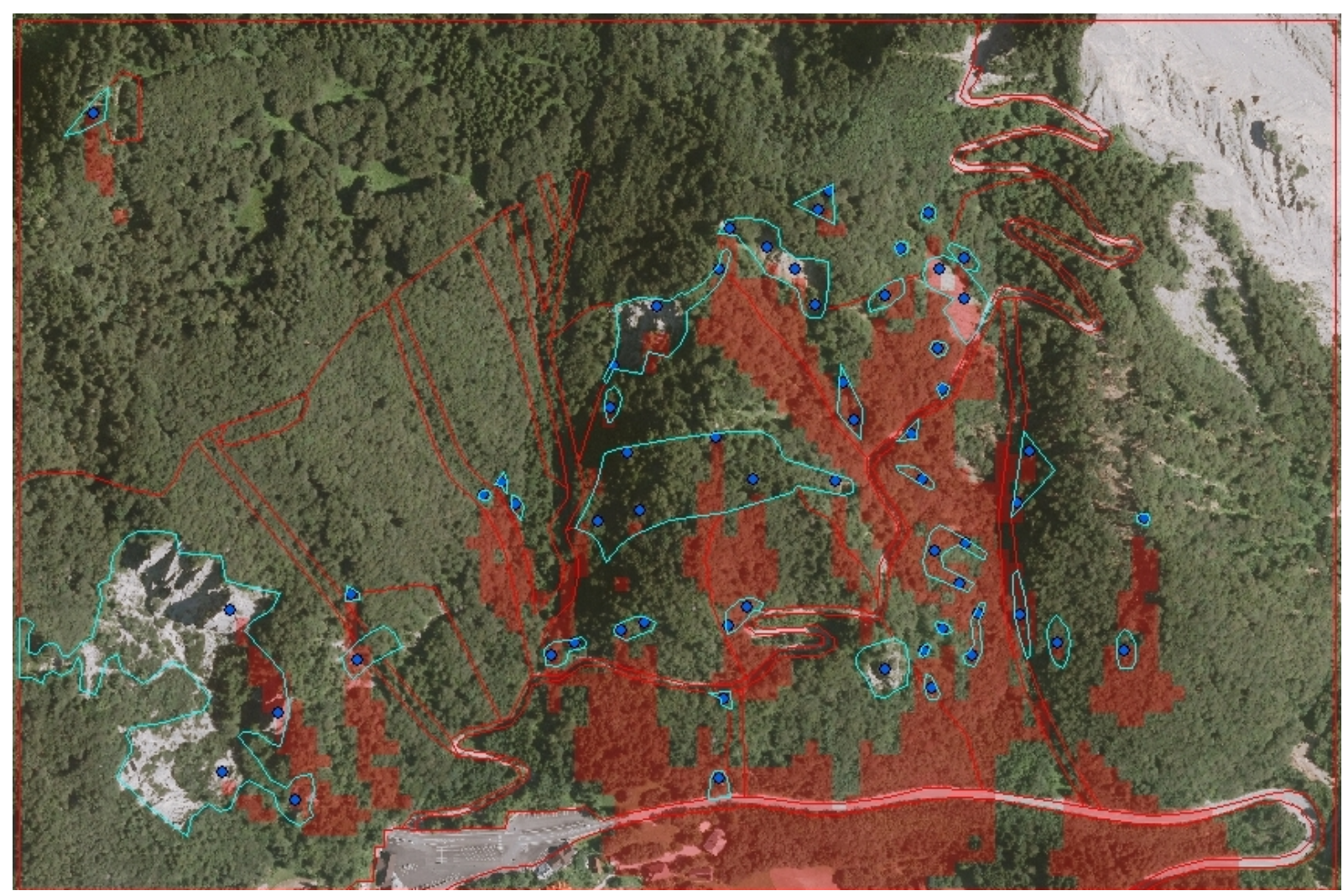

Figure A1. The map of rock source areas (coloured light blue), source points (coloured dark blue) and the maximal rockfall reach on the main road produced with the shadow angle method (red colour). Red lines represent borders of roughness polygons.

Table A1. Rockfor.NET results for sources that endanger the regional or forestry road.

\begin{tabular}{cc}
\hline Source & Maximum kinetic energy of the rock $(\mathbf{k J})$ \\
\hline 0 & 100 \\
1 & 155 \\
$2 \_2$ & 50 \\
$2 \_3$ & 150 \\
\hline
\end{tabular}


Table A1. Cont.

\begin{tabular}{cc}
\hline Source & Maximum kinetic energy of the rock $(\mathbf{k J})$ \\
\hline 7 & 150 \\
9 & 100 \\
10 & 100 \\
$12 \_2$ & 100 \\
$12 \_3$ & 100 \\
15 & 200 \\
24 & 100 \\
25 & 100 \\
$27 \_1$ & 150 \\
$27 \_2$ & 150 \\
33 & 50 \\
34 & 177 \\
35 & 47 \\
$36 \_3$ & 144 \\
37 & 99 \\
$38 \_3$ & 100 \\
$38 \_4$ & 100 \\
$38 \_5$ & 100 \\
\hline
\end{tabular}

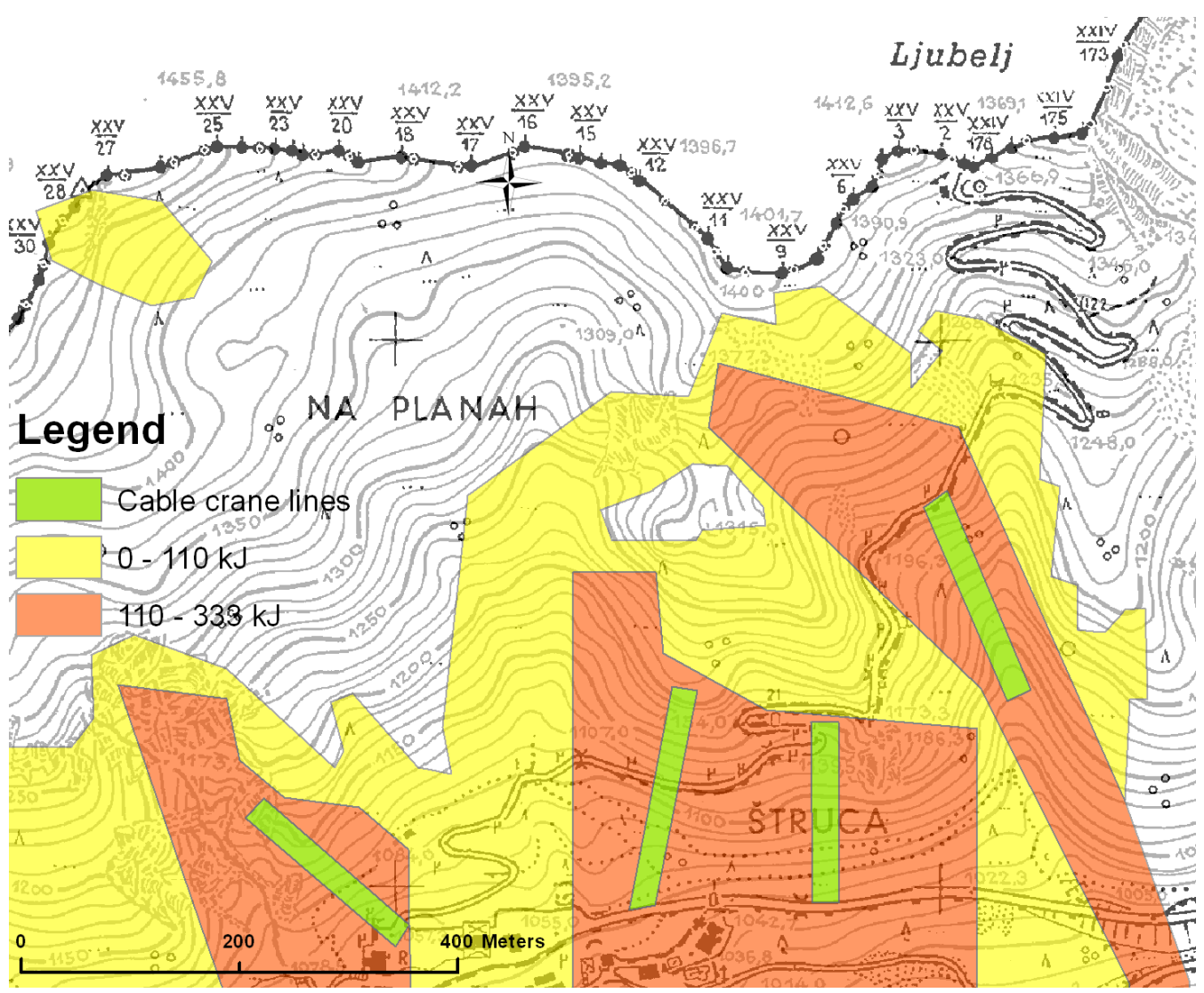

Figure A2. Three susceptibility areas delimited according to Rockyfor3D mean kinetic energy results for non-forested slope. Imaginary cable crane corridors used for Rockyfor3D simulations are coloured green. 


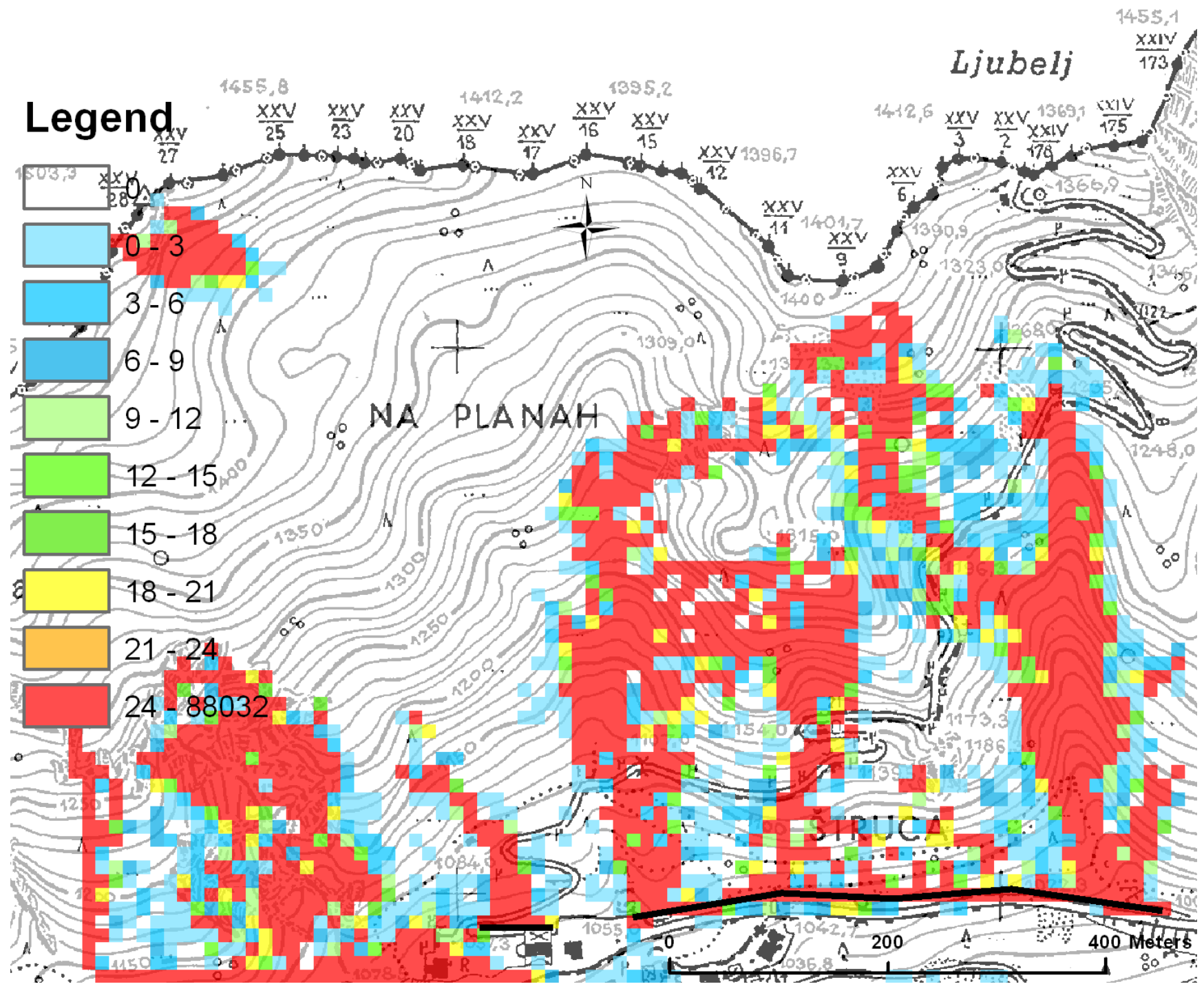

Figure A3. Number of deposited rocks for current forest scenario with rockfall retaining nets ( $3 \mathrm{~m}$ high, resistance $500 \mathrm{~kJ}$, shown as black line above the road).

\section{References}

1. Motta, R.; Haudemand, J.C. Protective forests and silvicultural stability an example of planning in the Aosta valley. Mt. Res. Dev. 2000, 20, 74-81.

2. Mayer, H.; Ott, E. Gebirgswaldbau, Schutzwaldpflege. Ein Waldbaulicher Beitrag zur Landschaftsökologie und Zum Umweltschutz; Gustav Fischer Verlag: Stuttgart, Germany, 1991; p. 587.

3. Brang, P. Resistance and elasticity: Promising concepts for the management of protection forests in the European Alps. For. Ecol. Manag. 2001, 145, 107-119.

4. Krauchi, N.; Brang, P.; Schonenberger, W. Forests of mountainous regions: Gaps in knowledge and research needs. For. Ecol. Manag. 2000, 132, 73-82.

5. Weiss, G. Evaluation of policy instruments for protective forest management in Austria. For. Policy Econ. 2000, 1, 243-255. 
6. Brang, P.; Schönenberger, W.; Frehner, M.; Schwitter, R.; Thormann, J.J.; Wasser, B. Management of protection forests in the European Alps: An overview. For. Snow Landsc. Res. 2006, 80, $23-44$.

7. Gauquelin, X.; Courbaud, B. Guide des Sylvicultures de Montagne Pour les Alpes du Nord Françaises; Cemagref, ONF: Grenoble, France, 2006.

8. Stokes, A.; Salin, F.; Kokutse, A.D.; Berthier, S.; Jeannin, H.; Mochan, S.; Dorren, L.; Kokutse, N.; Abd Ghani, M.; Fourcaud, T. Mechanical resistance of different tree species to rockfall in the French Alps. Plant Soil 2005, 278, 107-117.

9. Jancke, O.; Dorren, L.K.; Berger, F.; Fuhr, M.; Köhl, M. Implications of coppice stand characteristics on the rockfall protection function. For. Ecol. Manag. 2009, 259, 124-131.

10. Fidej, G.; Mikoš, M.; Rugani, T.; Jež, J.; Kumelj, Š.; Diaci, J. Assessment of the protective function of forests against debris flows in a gorge of the Slovenian Alps. iForest Biogeosci. For. 2015, 8 , 73-81.

11. Wehrli, A.; Brang, P.; Maier, B.; Duc, P.; Binder, F.; Lingua, E.; Ziegner, K.; Kleemayr, K.; Dorren, L. Management of protection forests in the Alps-An overview. Schweiz. Z. Forstwes. 2007, 158, $142-156$.

12. Zagas, T.D.; Raptis, D.I.; Zagas, D.T. Identifying and mapping the protective forests of southeast Mt. Olympus as a tool for sustainable ecological and silvicultural planning, in a multi-purpose forest management framework. Ecol. Eng. 2011, 37, 286-293.

13. Parise, M. Landslide hazard zonation of slopes susceptible to rock falls and topples. Nat. Hazards Earth Syst. Sci. 2002, 2, 37-49.

14. Guzzetti, F.; Reichenbach, P.; Ghigi, S. Rockfall hazard and risk assessment along a transportation corridor in the Nera valley, central Italy. Environ. Manag. 2004, 34, 191-208.

15. Dorren, L.K. A review of rockfall mechanics and modelling approaches. Prog. Phys. Geogr. 2003, 27, 69-87.

16. Dorren, L.; Berger, F.; Jonsson, M.; Krautblatter, M.; Mölk, M.; Stoffel, M.; Wehrli, A. State of the art in rockfall-Forest interactions. Schweiz. Z. Forstwes. 2007, 158, 128-141.

17. Guzzetti, F.; Crosta, G.; Detti, R.; Agliardi, F. Stone: A computer program for the three-dimensional simulation of rock-falls. Comput. Geosci. 2002, 28, 1079-1093.

18. Stoffel, M.; Wehrli, A.; Kuhne, R.; Dorren, L.K.A.; Perret, S.; Kienholz, H. Assessing the protective effect of mountain forests against rockfall using a 3D simulation model. For. Ecol. Manag. 2006, $225,113-122$.

19. Berger, F.; Dorren, L.K. Principles of the tool rockfor.Net for quantifying the rockfall hazard below a protection forest. Schweiz. Z. Forstwes. 2007, 158, 157-165.

20. Dorren, L.K.A.; Berger, F.; Imeson, A.C.; Maier, B.; Rey, F. Integrity, stability and management of protection forests in the European Alps. For. Ecol. Manag. 2004, 195, 165-176.

21. Frehner, M.; Wasser, B.; Schwitter, R. Nachhaltigkeit und Erfolgskontrolle im Schutzwald; Bundesamt für Umwelt BAFU: Bern, Switzerland, 2005.

22. Parise, M. Rock failures in karst. In Proceedings of the 10th International Symposium on Landslides, Xi'an, China, 15 June 2008; Chen, Z., Zhang, J.M., Eds.; CRC Press: Boca Raton, FL, USA; pp. 275-280.

23. Gutiérrez, F.; Parise, M.; de Waele, J.; Jourde, H. A review on natural and human-induced geohazards and impacts in karst. Earth-Sci. Rev. 2014, 138, 61-88. 
24. Dolenec, T.; Lojen, S.; Buser, S.; Dolenec, M. Stable isotope event markers near the permo-triassic boundary in the Karavanke Mountains (Slovenia). Geol. Croat. 1999, 52, 77-81.

25. Janowiak, M.K.; Nagel, L.M.; Webster, C.R. Spatial scale and stand structure in northern hardwood forests: Implications for quantifying diameter distributions. For. Sci. 2008, 54, 497-506.

26. Bachofen, H. Sustainable recruitment in uneven aged stands. Schweiz. Z. Forstwes. 2009, 160, 2-10.

27. Schütz, J.P. Der Plenterwald und weitere Formen strukturierter und gemischter Wälder; Parey: Berlin, Germany, 2001; p. 207.

28. EcorisQ. Available online: http://www.ecorisq.org/rockfor-net-en (accessed on 10 April 2015).

29. Dorren, L.K. Rockyfor3d (v 5.2) Revealed. Transparent Description of the Complete 3D Rockfall Model. Available online: http://www.ecorisq.org/docs/Rockyfor3D_v5_2_EN.pdf (accessed on 10 April 2015).

30. Motta, R. Impact of wild ungulates on forest regeneration and tree composition of mountain forests in the western Italian Alps. For. Ecol. Manag. 1996, 88, 93-98.

31. Ammer, C. Impact of ungulates on structure and dynamics of natural regeneration of mixed mountain forests in the Bavarian Alps. For. Ecol. Manag. 1996, 88, 43-53.

32. Dorren, L.K.A.; Maier, B.; Putters, U.S.; Seijmonsbergen, A.C. Combining field and modelling techniques to assess rockfall dynamics on a protection forest hillslope in the European Alps. Geomorphology 2004, 57, 151-167.

33. Bigot, C.; Dorren, L.A.; Berger, F. Quantifying the protective function of a forest against rockfall for past, present and future scenarios using two modelling approaches. Nat. Hazards 2009, 49, 99-111.

34. Mason, W. Implementing continuous cover forestry in planted forests: Experience with sitka spruce (Picea sitchensis) in the British Isles. Forests 2015, 6, 879-902.

35. Wehrli, A.; Dorren, L.K.; Berger, F.; Zingg, A.; Schönenberger, W.; Brang, P. Modelling long-term effects of forest dynamics on the protective effect against rockfall. For. Snow Landsc. Res. 2006, $80,57-76$.

(C) 2015 by the authors; licensee MDPI, Basel, Switzerland. This article is an open access article distributed under the terms and conditions of the Creative Commons Attribution license (http://creativecommons.org/licenses/by/4.0/). 